\title{
A large outbreak of gastrointestinal illness at an open-water swimming event in the River Thames, London
}

\author{
V. HALL ${ }^{1,2,3 *}$, A. TAYE ${ }^{4}$, B. WALSH ${ }^{4}$, H. MAGUIRE ${ }^{2,3,5}$, J. DAVE ${ }^{6}$, \\ A. WRIGHT ${ }^{3}$, C. ANDERSON ${ }^{3}$ AND P. CROOK ${ }^{3}$ \\ ${ }^{1}$ UK Field Epidemiology Training Programme, Public Health England, London, UK \\ ${ }^{2}$ European Programme for Intervention Epidemiology and Training (EPIET), European Centre for Disease \\ Control, Stockholm, Sweden \\ ${ }^{3}$ Field Epidemiology Service - London, Public Health England, London, UK \\ ${ }_{5}^{4}$ South West London Health Protection Team, Public Health England, London, UK \\ ${ }^{5}$ Department of Infection and Population Health, University College London, London, UK \\ ${ }^{6}$ London Public Health Laboratory, Public Health England, London, UK
}

Received 18 July 2016; Final revision 18 November 2016; Accepted 18 December 2016; first published online 6 February 2017

\section{SUMMARY}

Open-water swimming is increasingly popular, often in water not considered safe for bathing. Limited evidence exists on the associated health risks. We investigated gastrointestinal illness in 1100 swimmers in a River Thames event in London, UK, to describe the outbreak and identify risk factors. We conducted a retrospective cohort study. Our case definition was swimmers with any: diarrhoea, vomiting, abdominal cramps lasting $\geqslant 48 \mathrm{~h}$, nausea lasting $\geqslant 48 \mathrm{~h}$, with onset within 9 days after the event. We used an online survey to collect information on symptoms, demographics, pre- and post-swim behaviours and open-water experience. We tested associations using robust Poisson regression. We followed up case microbiological results. Survey response was $61 \%$, and attack rate 53\% (338 cases). Median incubation period was $34 \mathrm{~h}$ and median symptom duration 4 days. Five cases had confirmed microbiological diagnoses (four Giardia, one Cryptosporidium). Wearing a wetsuit [adjusted relative risk (aRR) 6.96, 95\% confidence interval (CI) 1.04 46.72] and swallowing water (aRR 1.42, 95\% CI 1.03-1.97) were risk factors. Recent river-swimming (aRR $0 \cdot 78,95 \%$ CI $0 \cdot 67-0 \cdot 92$ ) and age $>40$ years (aRR $0 \cdot 83,95 \%$ CI $0 \cdot 70-0 \cdot 98$ ) were protective. Action to reduce risk of illness in future events is recommended, including clarification of oversight arrangements for future swims to ensure appropriate risk assessment and advice is provided.

Key words: Community epidemics, gastrointestinal infections, water (quality), waterborne infections.

\section{INTRODUCTION}

Across the UK and in other countries, open-water swimming, where individuals swim in 'wild' settings

\footnotetext{
* Author for correspondence: Ms. V. Hall, c/o Paul Crook, Field Epidemiology Service - London, Public Health England, Skipton House, 80 London Road, London SE1 6LH, UK. (Email: victoria.hall4@nhs.net)
}

such as rivers, lakes and the sea, often in organized mass-participation events, is growing in popularity [1]. According to one website listing European openwater swimming events, between 2010 and 2014 the number almost doubled, from 971 to 1775 [2]. With an increasingly sedentary and obese population [3], this increased public participation in sporting events is a positive public health development, to be encouraged. However, health risks may present given that 
some of these events are organized in water that is not classified as safe for bathing. High attack rates of gastrointestinal illness have been reported in previous open-water events $[4,5]$.

In 2012 there were at least seven mass-participation swimming events organized in the River Thames, a major river that flows through the biggest city in Europe. The River Thames is not categorized as bathing water by the Environment Agency (England), and therefore is not considered safe for bathing. While efforts to improve the River Thames water quality continue, the river still periodically receives influxes of raw untreated sewage through the system of Combined Sewer Overflows (CSOs) during heavy rainfall [6].

Prior to Friday 19 October 2012, the then Health Protection Agency (HPA), [now Public Health England (PHE)], had not been made aware of any outbreaks related to an open-water swim in the River Thames.

On Friday 19 October 2012 the then HPA London Regional Epidemiology Unit (now the PHE Field Epidemiology Service) was informed of a patient who had been hospitalized on 17 October with severe headache, nausea, fever and sweating, and had reported swimming recently in a large swimming event in the River Thames. Through interviewing the index patient and two of their contacts who also swam and had been symptomatic, we identified a Facebook event page where around 40 other swimmers had reported illness following the event.

The event took place on Sunday 7 October 2012 and was a 2.25-mile organized swim between Hampton Court and Kingston Bridge in the River Thames in London. There were 1100 swimmers with varied experience, from experienced triathletes to charity fundraising first-timers. The organizers were a professional sports event company who regularly organized mass-participation sporting events such as swims, triathlons, and runs nationwide.

We conducted an epidemiological investigation aiming to describe the outbreak and to identify potential risk factors in order to inform public health action to reduce the risk of illness in swimmers in similar events in the future.

\section{METHODS}

\section{Study design}

We conducted a retrospective cohort study, defining our cohort as all swimmers participating in the Hampton Court Swim in the River Thames on 7 October 2012.

\section{Case definition}

We defined an outbreak case as a swimmer who was ill within 9 days after the race with any of the following symptoms: diarrhoea ( $\geqslant 3$ loose stools), vomiting, abdominal cramps lasting $\geqslant 48 \mathrm{~h}$ or nausea for $\geqslant 48$ h. The 9-day time limit for symptom onset was set using 'The Second Study of Infectious Intestinal Disease in the Community' to estimate the baseline incidence of gastrointestinal illness in the cohort and assess the number of days where the incidence exceeded the baseline [7]. Individuals who met the above case definition were excluded from the dataset if they met the following exclusion criteria: (i) symptom onset preceded the swim, (ii) had travelled outside the UK in the 7 days before symptom onset, or (iii) a member of their household was ill with diarrhoea and vomiting in the 7 days before symptom onset.

\section{Data collection}

\section{Environmental}

We contacted the Environment Agency and the drinking-water company, Thames Water, to identify available environmental data on the chemical and microbiological quality of the water in the River Thames on or around the race day. We also requested a map of the distribution of CSOs along the race course. We contacted colleagues in the Centre for Radiation, Chemical and Environmental Hazards (CRCE) to identify whether any chemical incidents had been reported in the River Thames on or around the race day. We contacted the UK Meteorological Office to obtain records of the weather conditions in the Thames catchment area in the 5 days preceding the event.

\section{Epidemiological}

We developed an online questionnaire using Select Survey ${ }^{\mathrm{TM}}$ software (https://surveys.phe.org.uk/). The questionnaire was circulated via email to all participants by the event organizers 23 days after the event. Participants were given 3 weeks to complete the questionnaire and an email reminder was sent after 2 weeks. Participants were asked for their demographic information, whether they had been unwell, and if so for clinical symptoms and microbiological test results.

The questionnaire included questions on 20 exposure variables that were considered to be potentially associated with illness (see Supplementary material). We identified possible exposures through discussion 
with colleagues, the race organizers and a brief literature review of similar outbreak investigations. Questions were included on behaviours that may have affected ingestion of water during or after the race and participants' previous experience of open-water swimming. This included race start time, swimming stroke, swallowing water while swimming, and post-event behaviours such as timing of handwashing or eating and drinking before handwashing. Swimmers were also asked if they had experienced illness following previous open-water swims. We piloted the questionnaire among open-water swimmer staff at the event organizers.

\section{Microbiological}

Participants were asked in the questionnaire whether they had submitted any samples for microbiological testing. Where samples had been submitted we contacted the relevant microbiological laboratories to obtain details of tests undertaken and results obtained and to find out whether any stool samples remained in storage. If stool samples remained available we sent them to the London Regional Microbiological laboratory to undergo a comprehensive microbiological and virology screen.

\section{Data analysis}

We exported the survey results from Select Survey into MS Excel (Microsoft Corp., USA) and then imported them into Stata v. 12 (StataCorp., USA) for data cleaning and analysis. We described the outbreak by time, place and person. We compared characteristics of cases and non-cases using appropriate significance tests (e.g. rank-sum test and $\chi^{2}$ test).

We conducted univariate analysis using robust Poisson regression for each exposure variable and the binary outcome variable-case or not a case, enabling relative risks (RRs) to be estimated [8]. Where appropriate, we analysed dose response using univariate robust Poisson regression (e.g. amount of water swallowed) and tested for significance using the $\chi^{2}$ test. We conducted stratified analysis on the variable emerging as the strongest risk factor in univariate analysis to explore if other variables were confounding this association and also to look at the effect of 'swallowed water' on post-race hygiene behaviours.

We then included factors associated with illness at $P<0.2$ in univariate analysis in a backward stepwise multivariable robust Poisson regression model, to derive adjusted relative risks (aRRs) [9]. We controlled variable exclusion by examining the change in RRs and using likelihood ratio tests to compare the goodness of fit of the model with a given variable excluded with that of the model before the variable was excluded. We included both apparent risk factors and protective factors in the model.

\section{RESULTS}

\section{Environmental results}

No chemical incident affecting water quality in the River Thames around the time of the race was reported by either the Environment Agency or the CRCE.

As the River Thames is not classified as bathing water by the Environment Agency and no routine microbiological testing is therefore conducted by the Environment Agency, they were unable to provide us with any data on what microorganisms were in the water on race day. The drinking-water company, Thames Water, do routinely test for Giardia cysts and Cryptosporidium oocysts in the water from their intake sites, and they informed us that they did not observe any unusual increase in frequency around race day. Thames Water also informed us that there were no acute occurrences of spillages of undiluted raw sewage into the river from the sewage treatment works in the days prior to the race.

The organizers report independently conducting water testing prior to the event through a private laboratory in London, taking samples on 5 October and 7 October at the race start location. The organizers reported that these results were 'normal'. The organizers had previously rescheduled the race from July to October following concerns about safety (flow speed) after high rainfall in July.

Data provided by the UK Meteorological Office showed high rainfall was recorded in weather stations in the Thames Valley area in the days preceding the event, with $18.4 \mathrm{~mm}$ recorded in High Wycombe and $17.8 \mathrm{~mm}$ in Reading on 5 October, compared to an average daily rainfall in October of $2-3 \mathrm{~mm}$ in the Thames Valley. In the week before the race the Environment Agency had put up red boards on the River Thames, meaning that the river was effectively closed for recreational use due to safety concerns. By the day of the event water flow had improved and the river was given an amber rating by the Environment Agency. 
Table 1. Description of survey respondents meeting the case definition in the Thames swim outbreak, London 2012

\begin{tabular}{ll}
\hline \hline & $\begin{array}{l}\text { Proportion of total cases } \\
(N=338) \text { exposed, } n(\%)\end{array}$ \\
Descriptive factor & $213(63)$ \\
Sex & \\
$\quad$ Male & $137(41)$ \\
Age & \\
Over 40 years (cohort median & \\
age 40) & \\
Self-reported open-water & \\
swimming experience & $65(19)$ \\
Beginner & $264(78)$ \\
Symptoms & $254(75)$ \\
Nausea & $237(70)$ \\
Diarrhoea & $193(57)$ \\
Abdominal cramps & $152(45)$ \\
Vomiting & $142(42)$ \\
Sweats & $118(35)$ \\
Fever & $10(3)$ \\
Headache & $7(2)$ \\
Rash & \\
Eye infection & $1(0 \cdot 3)$ \\
Microbiological diagnoses & $2 *(0 \cdot 6)$ \\
Cryptosporidium & $338(100 \%)$ \\
Giardia & \\
Total cases &
\end{tabular}

* In addition to the two cases of Giardia identified among survey respondents, two cases were reported from swimmers who did not complete the survey.

\section{Epidemiological results}

Survey response

The online survey received 763 responses, of which 675 were valid, a survey response of $61 \%$. After applying the exclusion criteria, 636 respondents were included in the analytical study.

\section{Description of cases}

A total of 338 respondents (53\%) met the case definition and are described in Table 1. The most common reported symptoms were nausea $(78 \%)$, diarrhoea $(75 \%)$ and abdominal cramps $(70 \%)$ (Table 1$)$. The median duration of symptoms was 4 days [range 136 days, interquartile range (IQR) 2-7 days]. The median time from exposure to onset of the first symptoms in cases (the incubation period) was $34 \mathrm{~h}$ (range 4-227 h, IQR 23-44 h). Ninety-six percent of cases had symptom onset within 5 days of the event. A graph showing the distribution of onset times is provided in Figure 1.
Cases were younger than non-cases: 38 years for cases (IQR 31-46) and 41 years (IQR 35-48) for non-cases (rank-sum test, $P=0 \cdot 001$ ). No significant difference in attack rate by sex was observed $\left(\chi^{2}\right.$ test, $\left.P=0 \cdot 75\right)$.

Eight cases attended Accident \& Emergency departments and four were admitted overnight to hospital related to their illness. Seventy-six cases $(22 \%)$ visited their general practitioner because of symptoms related to the swim. Two-hundred and seventeen cases (64\%) took time off work due to illness. The mean number of days off work was 2·3 (range $0 \cdot 5-14$ days, IQR 1-3 days).

\section{Clinical microbiological results}

Forty-two respondents reported providing samples for microbiological testing, 37 of whom gave us permission to follow-up their results and results were obtained for 31. Over half of these samples were not tested for microbiology and instead were used for haematology and liver function tests. Microbiological testing was conducted on 15 samples: 15 were tested for Salmonella, Shigella and Campylobacter, nine for E. coli O157, nine for Cryptosporidium, eight for Giardia, and one or two for norovirus, rotavirus, adenovirus, hepatitis $\mathrm{A}$ and Leptospira (Table 2). We identified just one stool sample that was available to send to the London Public Health Laboratory for comprehensive microbiology and virology testing, and all test results were negative.

We identified four cases of giardiasis in swimmers, including two who did not participate in the survey, and one case of cryptosporidiosis. We did not identify any other positive microbiological results among swimmers.

\section{Epidemiological results}

Exposures associated with illness

Seven variables were associated with either an increased or decreased risk of illness in univariate analysis at a significance level of $P \leqslant 0 \cdot 05$ : wearing a wetsuit [RR 4.91, 95\% confidence interval (CI) 1.3318.15], swallowed any water (RR 1.53, 95\% CI $1 \cdot 10-2 \cdot 14)$, swam in a river open-water event in the last 24 months (RR 0.77, 95\% CI 0.67-0.89), aware of infection risks associated with open-water swimming (RR 0.78, 95\% CI 0.63-0.97); aged $>40$ years (i.e. over the median age of the cohort) (RR 0.79 , 95\% CI 0.68-0.92), swam in an open-water event in the Thames in the last 24 months (RR 0.79, 95\% CI $0.68-0.92)$, swam in any open-water event in the last 24 months (RR 0.84, 95\% CI 0.71-0.99) (Table 3). 


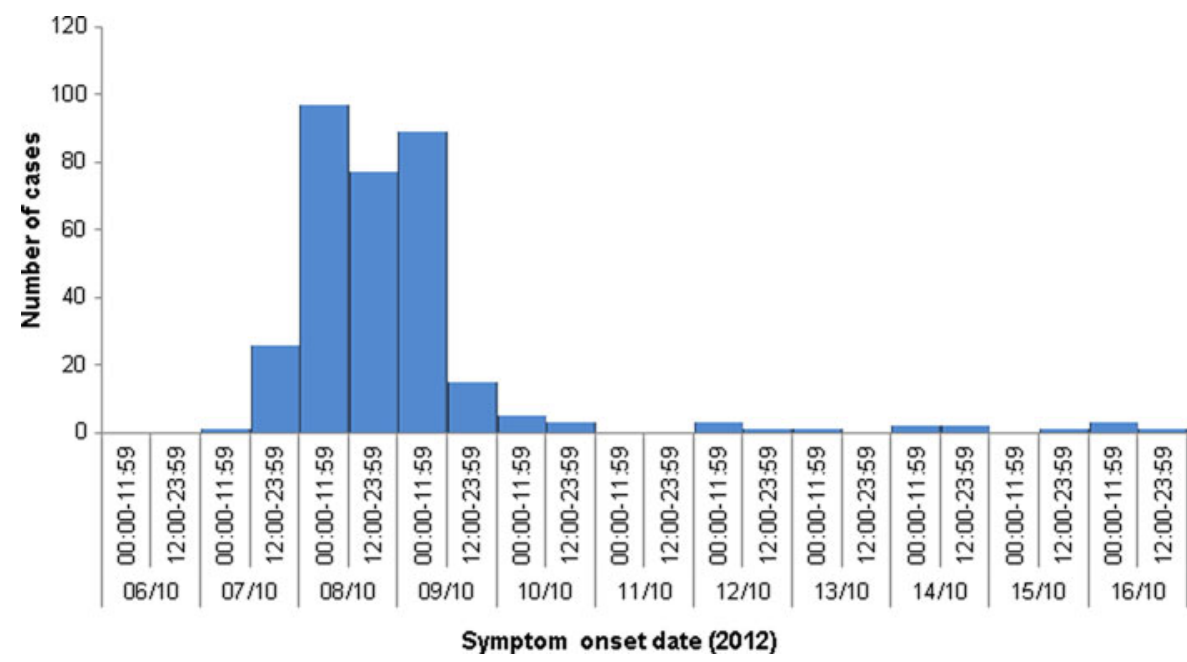

Fig. 1. Distribution of gastrointestinal illness symptom onset times in respondents meeting the case definition $(n=327)$, Thames open-water swim, October 2012.

Table 2. Description of the microbiological testing conducted and diagnoses obtained from respondents meeting the case definition in the Thames open-water swim, London $2012(N=338)$

\begin{tabular}{llll}
\hline \hline & $\begin{array}{l}\text { No. of } \\
\text { individuals with } \\
\text { samples tested }\end{array}$ & $\begin{array}{l}\text { Percent of } \\
\text { all 338 cases } \\
\text { tested }\end{array}$ & $\begin{array}{l}\text { Positive } \\
\text { results }\end{array}$ \\
\hline Salmonella & 15 & $4 \cdot 4$ & 0 \\
Shigella & 15 & $4 \cdot 4$ & 0 \\
Campylobacter & 15 & $4 \cdot 4$ & 0 \\
E. coli O157 & 9 & $2 \cdot 7$ & 0 \\
Cryptosporidium & 8 & $2 \cdot 4$ & 1 \\
Giardia & 9 & $2 \cdot 7$ & $2 *$ \\
Norovirus & 2 & $0 \cdot 6$ & 0 \\
Rotavirus & 2 & $0 \cdot 6$ & 0 \\
Adenovirus & 1 & $0 \cdot 3$ & 0 \\
Hepatitis A & 2 & $0 \cdot 6$ & 0 \\
Leptospira & 1 & $0 \cdot 3$ & 0 \\
\hline \hline
\end{tabular}

* In addition to the two cases of Giardia identified in survey respondents, two cases were reported from swimmers who did not complete the survey.

In stratified analysis we did not find that the association between illness and wearing a wetsuit was explained by swimmers' experience, age or previous recent open-water experience. Similarly, even after adjusting for the potential confounding factor 'swallowed water', we did not find post-race hygiene variables (washed hands within $30 \mathrm{~min}$ of swim, showered within $1 \mathrm{~h})$ to be significant protective factors.

No dose response was observed for the number of mouthfuls of water swallowed (Mantel-Haenszel odds test for trend, $P=0 \cdot 3585$ ).
Two of the seven variables associated with illness at significance level $P=0.05$ in univariate analysis: previously swam in the Thames and swam in any openwater event in the past 24 months were excluded from multivariable analysis due to collinearity with the variable 'previously swam in a river open-water event in the past 24 months', which was included in the model.

Four of the five variables associated with illness at significance level $P=0.05$ in univariate analysis remained significant in the final model; however, one variable: 'reported awareness of infection risks' was no longer significantly associated with illness after adjustment for the other variables.

In the final robust Poisson regression model two variables were found to be significantly associated with increased risk of illness following the swim $(P \leqslant 0 \cdot 05)$ : wearing a wetsuit (aRR 6.96, 95\% CI 1.04-46.72) and swallowing any water during the swim (aRR 1.42, 95\% CI 1.03-1.97) (Table 4). Two variables were associated with reduced risk of illness: previously swimming in a river open-water swim event in the past 24 months (aRR $0 \cdot 78,95 \%$ CI $0 \cdot 67-0 \cdot 92$ ) and age $>40$ years (aRR $0 \cdot 83,95 \%$ CI $0 \cdot 70-0 \cdot 98$ ).

\section{Illness associated with previous open-water swims}

Five-hundred and fifteen participants (81\%) reported that they had participated in another open-water swim event in the previous 24 months (Table 5), with $49 \%$ previously swimming in the Thames. The highest frequency of reported illness following swimming events was after swimming in the Thames 
Table 3. Factors investigated as potentially associated with illness in swimmers, Thames open-water swim, October 2012

\begin{tabular}{|c|c|c|c|c|c|c|}
\hline \multirow[b]{2}{*}{ Exposure variable } & \multicolumn{2}{|c|}{$\begin{array}{l}\text { Risk of } \\
\text { illness among } \\
\text { exposed }\end{array}$} & \multicolumn{2}{|c|}{$\begin{array}{l}\text { Risk of } \\
\text { illness among } \\
\text { unexposed }\end{array}$} & \multirow[b]{2}{*}{$\mathrm{RR}(95 \% \mathrm{CI})$} & \multirow[b]{2}{*}{$P$ value } \\
\hline & $\mathrm{I} 11 / n$ & $\%$ & $\mathrm{Ill} / n$ & $\%$ & & \\
\hline Wore a wetsuit* & $330 / 600$ & 55 & $2 / 18$ & 11 & $4 \cdot 91(1 \cdot 33-18 \cdot 15)$ & $<0 \cdot 001$ \\
\hline Swallowed any water* & $246 / 465$ & 53 & $24 / 69$ & 35 & $1 \cdot 53(1 \cdot 10-2 \cdot 14)$ & $0 \cdot 004$ \\
\hline Washed hands within 30 min of race finish** & $31 / 48$ & 65 & $293 / 563$ & 52 & $1 \cdot 24(0 \cdot 99-1 \cdot 56)$ & $0 \cdot 093$ \\
\hline Beginner to open-water swimming & $65 / 116$ & 56 & $262 / 503$ & 52 & $1 \cdot 08(0 \cdot 90-1 \cdot 29)$ & $0 \cdot 443$ \\
\hline Ever sick after a swim (in last 24 months) & $48 / 86$ & 56 & $292 / 550$ & 53 & $1 \cdot 06(0 \cdot 86-1 \cdot 29)$ & $0 \cdot 593$ \\
\hline Used antibacterial hand gel within $30 \mathrm{~min}$ after race & $27 / 48$ & 56 & $300 / 566$ & 53 & $1 \cdot 06(0 \cdot 82-1 \cdot 38)$ & 0.666 \\
\hline Smoked within 30 min after race** & $2 / 7$ & 29 & $306 / 578$ & 53 & $0.53(0 \cdot 17-1 \cdot 73)$ & $0 \cdot 190$ \\
\hline Showered within $1 \mathrm{~h}$ of race finish** & $11 / 27$ & 41 & $315 / 583$ & 54 & $0 \cdot 76(0 \cdot 48-1 \cdot 20)$ & $0 \cdot 188$ \\
\hline $\begin{array}{l}\text { Swam in an open-water event in a river in the } \\
\text { last } 24 \text { months* }\end{array}$ & $165 / 350$ & 47 & $174 / 286$ & 61 & $0.77(0.67-0.89)$ & $<0 \cdot 001$ \\
\hline Aware of infection risks* & $289 / 566$ & 51 & $33 / 50$ & 66 & $0.78(0.63-0.97)$ & $0 \cdot 048$ \\
\hline Aged $>40$ years $(\text { median age } 40)^{*}$ & $137 / 298$ & 46 & $199 / 338$ & 59 & $0.79(0.68-0.92)$ & $0 \cdot 002$ \\
\hline $\begin{array}{l}\text { Swam in an open-water event in the Thames in } \\
\text { the last } 24 \text { months* }\end{array}$ & $146 / 310$ & 47 & $192 / 326$ & 59 & $0.79(0.68-0.92)$ & $0 \cdot 002$ \\
\hline Swam in any open-water swim event in the last 24 months* & $263 / 515$ & 51 & $74 / 121$ & 61 & $0 \cdot 84(0 \cdot 71-0 \cdot 99)$ & $0 \cdot 050$ \\
\hline Had a drink after race before washing hands** & $301 / 548$ & 55 & $42 / 68$ & 62 & $0 \cdot 84(0 \cdot 68-1 \cdot 03)$ & $0 \cdot 121$ \\
\hline Swam with water in mouth & $281 / 540$ & 52 & $47 / 79$ & 59 & $0.87(0 \cdot 72-1 \cdot 07)$ & $0 \cdot 226$ \\
\hline Ate food after race before washing hands & $229 / 441$ & 52 & $98 / 179$ & 55 & $0.94(0 \cdot 80-1 \cdot 11)$ & $0 \cdot 475$ \\
\hline Male & $213 / 401$ & 53 & $122 / 230$ & 53 & $0.98(0 \cdot 84-1 \cdot 14)$ & $0 \cdot 754$ \\
\hline In water $>40$ min (median swim duration) & $142 / 267$ & 53 & $181 / 335$ & 54 & $0.98(0 \cdot 84-1 \cdot 14)$ & $0 \cdot 780$ \\
\hline \multicolumn{7}{|l|}{ Stroke } \\
\hline Breaststroke (head above water) & $41 / 80$ & 51 & $84 / 150$ & 56 & $0.92(0 \cdot 71-1 \cdot 18)$ & $0 \cdot 491$ \\
\hline Breaststroke (head under water) & $47 / 87$ & 54 & $91 / 159$ & 57 & $0.94(0 \cdot 75-1 \cdot 20)$ & 0.628 \\
\hline Backstroke & $11 / 20$ & 55 & $99 / 170$ & 58 & $0.94(0.63-1.43)$ & $0 \cdot 782$ \\
\hline Front crawl & $317 / 599$ & 53 & $1 / 4$ & 25 & $2 \cdot 21(0 \cdot 39-11 \cdot 58)$ & $0 \cdot 265$ \\
\hline \multicolumn{7}{|l|}{ Start time } \\
\hline 1st session $(08: 30)$ & $27 / 59$ & 46 & \multicolumn{4}{|c|}{ First session is the reference group } \\
\hline 2nd session $(08: 40)$ & $36 / 62$ & 58 & $27 / 59$ & 46 & $1 \cdot 27(0 \cdot 89-1 \cdot 80)$ & $0 \cdot 182$ \\
\hline 3rd session $(08: 50)$ & $40 / 63$ & 63 & $27 / 59$ & 46 & $1 \cdot 39(0.99-1.94)$ & $0 \cdot 056$ \\
\hline 4th session $(09: 00)$ & $21 / 48$ & 44 & $27 / 59$ & 46 & $0.96(0.63-1 \cdot 46)$ & $0 \cdot 836$ \\
\hline 5 th session $(09: 10)$ & $36 / 58$ & 62 & $27 / 59$ & 46 & $1.36(0.94-1.90)$ & $0 \cdot 082$ \\
\hline 6 th session $(09: 20)$ & $33 / 54$ & 61 & $27 / 59$ & 46 & $1.34(0.94-1.90)$ & $0 \cdot 105$ \\
\hline 7 th session $(09: 30)$ & $30 / 59$ & 51 & $27 / 59$ & 46 & $1 \cdot 11(0 \cdot 76-1 \cdot 61)$ & $0 \cdot 581$ \\
\hline 8th session $(09: 40)$ & $24 / 57$ & 42 & $27 / 59$ & 46 & $0.92(0.61-1.39)$ & 0.692 \\
\hline 9 th session $(09: 50)$ & $36 / 63$ & 57 & $27 / 59$ & 46 & $1 \cdot 24(0 \cdot 88-1 \cdot 77)$ & $0 \cdot 215$ \\
\hline 10th session $(10: 00)$ & $21 / 55$ & 38 & $27 / 59$ & 46 & $0.83(0.54-1 \cdot 29)$ & $0 \cdot 416$ \\
\hline 11th session $(10: 10)$ & $26 / 42$ & 62 & $27 / 59$ & 46 & $1.35(0.94-1.95)$ & $0 \cdot 105$ \\
\hline Not known & $8 / 12$ & 67 & $27 / 59$ & 46 & $1 \cdot 46(0 \cdot 89-2 \cdot 37)$ & $0 \cdot 130$ \\
\hline
\end{tabular}

RR, Relative risk; CI, confidence interval.

*Significant at $P \leqslant 0 \cdot 05, * *$ significant at $P \leqslant 0 \cdot 2$.

(17\%). The type of illness experienced was not specified in the questionnaire.

\section{DISCUSSION}

\section{Key findings}

Swimmers in open-water events in water not classified as bathing-water quality face a considerable risk of gastrointestinal illness. At this event the attack rate was at least 33\% (assuming non-responders to the survey were not ill). Similarly high attack rates have been reported in other open-water swims, with $85 \%$ of swimmers ill with norovirus after an event at Strathclyde Loch, Scotland in 2012 [4] and 42\% of swimmers ill with gastroenteritis at a triathlon in Copenhagen in 2010 [5]. 
Table 4. Factors associated with illness in swimmers, Thames open-water swim, October 2012, results from final multivariable robust Poisson regression model

\begin{tabular}{|c|c|c|c|}
\hline Exposure & $\begin{array}{l}\text { Adjusted } \\
\text { RR }\end{array}$ & $95 \% \mathrm{CI}$ & $P$ value \\
\hline Wore wetsuit & $6 \cdot 96$ & $1 \cdot 04-46 \cdot 72$ & $0 \cdot 046$ \\
\hline Swallowed any water & $1 \cdot 42$ & $1 \cdot 03-1 \cdot 97$ & 0.033 \\
\hline $\begin{array}{l}\text { Swam in a river } \\
\text { open-swim event in } \\
\text { previous } 24 \text { months }\end{array}$ & $0 \cdot 78$ & $0.67-0.92$ & 0.003 \\
\hline Aged $>40$ years & $0 \cdot 83$ & $0 \cdot 70-0.98$ & 0.033 \\
\hline
\end{tabular}

$\mathrm{RR}$, Relative risk; CI, confidence interval.

Table 5. Frequency of illness experienced by survey respondents following previous open-water events, Thames open-water swim, October 2012

\begin{tabular}{|c|c|c|}
\hline Open-water setting & $\begin{array}{l}\text { Respondents who } \\
\text { participated in } \\
\text { other open-water } \\
\text { events, } n(\%)\end{array}$ & $\begin{array}{l}\text { Proportion of } \\
\text { respondents ill } \\
\text { following previous } \\
\text { events }(\%)\end{array}$ \\
\hline Thames & $310(49 \%)$ & 17 \\
\hline $\begin{array}{l}\text { River (excluding } \\
\text { Thames) }\end{array}$ & $110(17 \%)$ & 4 \\
\hline Lake & $423(67 \%)$ & 7 \\
\hline Sea & $236(37 \%)$ & 5 \\
\hline
\end{tabular}

No causal organism was identified, with microbiological testing results obtained for $<10 \%$ of cases, of whom only five received diagnoses. While four cases of Giardia and one case of Cryptosporidium were diagnosed (among nine tested for Giardia and eight tested for Cryptosporidium), given the relatively short median incubation period, these were unlikely to have been the main causal organism. Based on the characteristics of cases, the absence of positive microbiological test results and knowledge of circulating seasonal pathogens, a gastrointestinal virus is a possible predominant causal pathogen [10].

Epidemiological studies have found that swimming, and to a lesser extent, rowing and canoeing, in open water is associated with an increased risk of gastrointestinal illness [11-14], even in locations that meet bathingwater standards [15-17]. As would be expected, given the range of 'open-water' settings, risk varies by location, largely determined by the source and catchment area. The course of the River Thames, in common with some other rivers, is distributed with CSOs, which under heavy rainfall can relieve pressure in the system by releasing raw sewage directly into the river. In one study that undertook regular microbiological testing on water sampled from the Thames over almost a 2-year period, human pathogens were consistently detected, with the pathogen load especially high following sewage discharge from CSOs [13]. The health consequence of this is illustrated by $17 \%$ of respondents in our survey reporting previous illness following swimming in the Thames.

National and international bathing-water standards are an important indicator of the likely water quality, and in locations, such as the Thames, that are not classified as bathing water, and therefore not required to meet these standards, it is clear that the risk associated with swimming is greater. This prompts the question of whether it is advisable for mass-participation events to be organized in locations that are not designated as safe for bathing. A secondary question is whether swimmers are sufficiently aware of the risk, or whether they are falsely reassured by the fact that a mass-participation event is being organized, assuming this means it is safe to do so.

As open and uncontrolled sites, risk of gastrointestinal illness can fluctuate greatly even at the same open-water setting, with rainfall and discharge from CSOs being an important factor [18, 19]. In 2010 the attack rate of gastroenteritis at a Copenhagen triathlon, occurring after heavy rainfall and CSO discharge, was $42 \%$ compared to $8 \%$ in 2011 , occurring at the same race course but without the preceding heavy rain [5]. It is possible therefore that the preceding weather conditions in this outbreak may have meant the pathogen load and risk of illness on the race day were especially high. This fluctuation suggests the potential for risk reduction through appropriate risk management, namely postponing events following adverse conditions, involving timely communication between those conducting the risk assessment and those organizing the event.

This outbreak investigation has revealed a lack of clarity over responsibilities for managing infectious disease health risks associated with the organization of mass-participation swims in the River Thames, which may be shared by other locations nationally and internationally. Given the trend for increasing public participation in open-water swimming events, there is the potential for other large-scale outbreaks to occur. A more proactive approach from agencies involved in public health and managing open-water settings and event organizers to clarify oversight and risk management arrangements for future open-water swims, has the potential to reduce the risk of illness. 
This outbreak investigation, which convened key stakeholders to explore the causes for this outbreak and in doing so, started to identify precautions for future events, is an example of effective practice. It would be ideal to engage appropriate stakeholders in planning future events to try and reduce potential health risks.

Another important consideration is what openwater swimmers can do to protect themselves from illness. In this study we investigated a range of potential protective and risk factors; however, only four associated factors emerged, and their contribution to developing guidance is limited. Two factors were found to increase risk of illness: wearing a wetsuit and swallowing water, and two potential protective factors emerged: being aged $>40$ years and having swam in a previous river open-water event in the last 24 months. The two protective factors could potentially be explained by previous exposure to the causal organism offering greater resistance to infection or perhaps suggesting greater open-water swimming experience or better technique; although self-reported open-water swimming experience was not found to be associated in analysis. Importantly, neither factor can be mobilized to inform guidance. Of the two potential risk factors, advising swimmers to avoid swallowing water is obvious. The association with wetsuits requires more consideration. Wetsuits retain water and can promote the growth of microorganisms such as bacteria and fungi from river water; therefore, handling the wetsuit after the event may create and prolong an infection risk [20]. Issuing advice regarding post-swim wetsuit handling and even wetsuit washing stations should be considered for infection prevention. However, the confidence interval associated with wetsuits was substantial, and with just 18 respondents not wearing a wetsuit, residual confounding may be a factor; therefore, the potential association with wetsuits should be treated cautiously. While we investigated a range of factors, including post-event showering and handwashing, which could have informed advice to swimmers, none of these were found to be associated with illness. While our investigation failed to inform an evidence base for developing advice, we consider that issuing pragmatic advice to swimmers including avoiding excessive swallowing of water and post-event handwashing would be beneficial.

\section{Limitations}

We did not identify a main causal organism, with few cases undergoing microbiological testing, and of those that did, few were tested for the most likely candidates (gastrointestinal viruses). Given the time between clinical sampling and survey completion, only one stool sample was available for comprehensive microbiological and viral screening at the Public Health laboratory. The absence of a main causal organism complicated the case definition, particularly setting a time threshold, which had to reflect the fact that while the majority of cases had an onset within $34 \mathrm{~h}$, the two organisms identified have long maximum incubation periods (25 days for Giardia and 12 days for Cryptosporidium) [10]. Consequently the case definition that was used, including a time threshold of 9 days, may have resulted in misclassification, overcounting or under-counting (missing more Giardia and Cryptosporidium) cases. However, we consider that this misclassification would have biased results towards the null.

The potential scale of this outbreak was first recognized by viewing communication on the event's Facebook webpage. It is possible that this publicity may have increased reporting of illness, with participants keen to attribute potential symptoms to the event once they became aware that others had reported symptoms. However, given that the case definition required people to have experienced significant gastrointestinal symptoms, we consider this unlikely to have contributed significantly to the attack rate.

As discussed above, we explored potential exposures and behaviours associated with illness, hoping to identify actions that could possibly protect future swimmers. However, few associations were detected, including no benefits of hygienic precautions such as handwashing. It is possible that our survey questions were insufficiently detailed or that recall bias played a role with 3 weeks elapsing between the event and the survey initiation.

\section{CONCLUSION}

We have reported a large outbreak of gastrointestinal illness affecting at least 338 of 1100 swimmers at an open-water swimming event in the River Thames in October 2012. No main causal organism was identified, although there were a small number of Giardia and Cryptosporidium diagnoses. The attack rate in survey participants was very high $(53 \%)$, and with high rates reported at other similar events, it is clear that swimmers in open-water events in water 
not classified as bathing-water quality face a considerable risk of gastrointestinal illness.

This investigation highlighted a lack of clarity over responsibilities for oversight and public health risk management for mass-participation swimming events in the Thames. This situation is unlikely to be unique to events in the River Thames. Evidence suggests there is opportunity to reduce the risk of illness associated with these events, whether by guiding choice of location or by being responsive to weather conditions. With open-water swimming growing in popularity we advocate a more proactive approach from agencies involved in public health and managing open-water settings and event organizers to clarify oversight and risk management arrangements for future open-water swims, in order to reduce the risk of illness.

Additionally, it may be possible for swimmers to reduce their risk of infection by following precautions; however, this study alone provides insufficient evidence to inform this. We consider that prospective participants at mass-participation events in water not designated as bathing quality should be informed of the potential health risks and advised to take pragmatic precautions, such as avoiding swallowing water and washing after the event.

We recommend that open-water event organizers, public health authorities and relevant agencies work together to raise awareness among swimmers of the risk of illness and pragmatic precautions, such as hand hygiene and wetsuit washing. This should include: providing prospective swimmers with information on associated health risks and the importance of hygienic precautions, providing appropriate hygiene facilities post-race. Furthermore more proactive communication between organizers and relevant agencies regarding potential water quality prior to events would help to refine risk assessments to guide whether events should be held or not. We also recommend further research, such as a prospective study, to explore risk factors and develop the evidence-base for interventions.

\section{SUPPLEMENTARY MATERIAL}

For supplementary material accompanying this paper visit https://doi.org/10.1017/S0950268816003393.

\section{ACKNOWLEDGEMENTS}

We gratefully acknowledge the support received during the outbreak organization from the following organizations: Human Race Limited; Thames Water; Environment Agency; UK Meteorological Office; London Borough of Kingston Environmental Health Department and London Borough of Richmond Environmental Health Department. We are also grateful to the event participants for completing the survey.

This research received no specific grant from any funding agency, commercial or not-for-profit sectors.

\section{DECLARATION OF INTEREST}

None.

\section{REFERENCES}

1. Laville S. Different strokes: open-water swimming takes the UK by storm. Guardian 18 August 2015.

2. Open Water Swimming in Europe. EU Event listing database (http://openwaterswimming.eu/). Accessed 10 May 2016.

3. The Health and Social Care Information Centre. Health Survey for England, 2014. London, 2015.

4. Logan J. The Strathclyde Loch norovirus outbreak. In the annual report of the Director of Public Health, 2013. NHS Lanarkshire Public Health, 2013.

5. Harder-Lauridsen NM, et al. Gastrointestinal illness among triathletes swimming in non-polluted versus polluted seawater affected by heavy rainfall, Denmark, 2010-2011. PLoS ONE 2013; 8(11): e78371.

6. Thames Water. London tideway improvements. (http:// www.thameswater.co.uk/about-us/2833.htm).

7. Tam CC, et al. Longitudinal study of infectious intestinal disease in the UK (IID2 study): incidence in the community and presenting to general practice. Gut 2012; 61: 69-77.

8. Zou G. Modified Poisson regression approach to prospective studies with binary data. American Journal of Epidemiology 2004; 159(7).

9. Bursac Z, et al. Purposeful selection of variables in logistic regression. Source Code for Biology and Medicine 2008; 3: 17.

10. Heymann D. (ed.) Control of Communicable Diseases Manual, 19th edn. Washington, DC, American Public Health Association, 2008.

11. Fewtrell L, Kay D. Recreational water and infection: a review of recent findings. Current Environmental Health Reports 2015; 2: 85-94.

12. Prüss A. Review of epidemiological studies on health effects from exposure to recreational water. International Journal of Epidemiology 1998; 27: 1-9.

13. Lane C, et al. The Thames Recreational Users Study: Final report 2007. UK: Health Protection Agency \& the City of London Port Health Authority, 2007.

14. Dorevitch $\mathbf{S}$, et al. Health risks of limited-contact water recreation. Environmental Health Perspectives 2012; 120: $192-197$.

15. van Asperen IA, et al. Risk of gastroenteritis among triathletes in relation to faecal pollution of fresh 
waters. International Journal of Epidemiology 1998; 27: 309-315.

16. Papastergiou $\mathbf{P}$, et al. Elevated bathing-associated disease risks despite certified water quality: a cohort study. International Journal of Environmental Research and Public Health 2012; 9: 1548-1565.

17. Wade TJ, et al. Do US environmental protection agency water quality guidelines for recreational waters prevent gastrointestinal illness? Environmental Health Perspectives 2003; 111: 1102-1109.
18. Colford JM, et al. Using rapid indicators for Enterococcus to assess the risk of illness after exposure to urban runoff contaminated marine water. Water Research 2012; 46: 2176-2186.

19. Yau VM, et al. Effect of submarine groundwater discharge on bacterial indicators and swimmer health at Avalon Beach, CA, USA. Water Research 2014; 59: 23-36.

20. Pearson H. Divers carry pathogens in their wetsuits. Nature News 25 May 2006. 